\title{
Neutronic Analysis of Candidate Accident-Tolerant Cladding Concepts in Pressurized Water Reactors
}

\author{
Nathan Michael George ${ }^{1}$, Kurt Terrani ${ }^{2}$, Jeff Powers ${ }^{3}$, Andrew Worrall ${ }^{3}$, Ivan Maldonado ${ }^{1}$ \\ ${ }^{1}$ Department of Nuclear Engineering, University of Tennessee Knoxville, \\ Knoxville, TN 37996-2300 \\ ${ }^{2}$ Fusion and Materials for Nuclear Systems Division, Oak Ridge National Laboratory, \\ Oak Ridge, TN 37831 \\ ${ }^{3}$ Reactor and Nuclear Systems Division, Oak Ridge National Laboratory, Oak Ridge, TN 37831
}

Number of Pages: 23

Number of Tables: 10

Number of Figures: 10

Primary Contact:

Nathan Michael George

ngeorge3@utk.edu

238 South Purdue Ave.

Oak Ridge, TN 37830

8148231146 


\begin{abstract}
A study analyzed the neutronics of alternate cladding materials in a pressurized water reactor (PWR) environment. Austenitic type 310 (310SS) and 304 stainless steels, ferritic Fe-20Cr-5Al $(\mathrm{FeCrAl})$ and $\mathrm{APMT}^{\mathrm{TM}}$ alloys, and silicon carbide $(\mathrm{SiC})$-based materials were considered and compared with Zircaloy-4. SCALE 6.1 was used to analyze the associated neutronics penalty/advantage, changes in reactivity coefficients, and spectral variations once a transition in the cladding was made. In the cases examined, materials containing higher absorbing isotopes invoked a reduction in reactivity due to an increase in neutron absorption in the cladding. Higher absorbing materials produced a harder neutron spectrum in the fuel pellet, leading to a slight increase in plutonium production. A parametric study determined the geometric conditions required to match cycle length requirements for each alternate cladding material in a PWR. A method for estimating the end of cycle reactivity was implemented to compare each model to that of standard Zircaloy-4 cladding. By using a thinner cladding of $350 \mu \mathrm{m}$ and keeping a constant outer diameter, austenitic stainless steels require an increase of no more than $0.5 \mathrm{wt} \%$ enriched ${ }^{235} \mathrm{U}$ to match fuel cycle requirements, while the required increase for $\mathrm{FeCrAl}$ was about $0.1 \%$. When modeling $\mathrm{SiC}$ (with slightly lower thermal absorption properties than that of Zircaloy), a standard cladding thickness could be implemented with marginally less enriched uranium ( $0.1 \%$ ). Moderator temperature and void coefficients were calculated throughout the depletion cycle. Nearly identical reactivity responses were found when coolant temperature and void properties were perturbed for each cladding material. By splitting the pellet into 10 equal areal sections, relative fission power as a function of radius was found to be similar for each cladding material. FeCrAl and 310SS cladding have a slightly higher fission power near the pellet's periphery due to the harder neutron spectrum in the system, causing more ${ }^{239} \mathrm{Pu}$ breeding. An economic assessment calculated the change in fuel pellet production costs for use of each cladding. Implementing $\mathrm{FeCrAl}$ alloys would increase fuel pellet production costs about $15 \%$ because of increased ${ }^{235} \mathrm{U}$ enrichment and the additional $\mathrm{UO}_{2}$ pellet volume enabled by using thinner cladding.
\end{abstract}

Key Words: Alternate Cladding, Accident Tolerant Fuel, FeCrAl, 310SS, SiC, PWR, fuel

\footnotetext{
${ }^{1}$ Notice: This manuscript has been authored by UT-Battelle, LLC, under Contract No. DE-AC0500OR22725 with the U.S. Department of Energy. The United States Government retains and the publisher, by accepting the article for publication, acknowledges that the United States Government retains a non-exclusive, paid-up, irrevocable, world-wide license to publish or reproduce the published form of this manuscript, or allow others to do so, for the United States Government purposes."
} 


\section{INTRODUCTION}

\section{I.A. Motivation for Consideration of Alternate Cladding Concepts}

Zirconium alloys initially were developed for use as nuclear fuel cladding in the US Navy's pressurized water reactors (PWRs) in the 1950s. Since that time, significant improvements to the alloys enable them to operate reliably in civilian boiling water reactors and PWRs [1]. The low parasitic neutron absorption in these alloys enables an optimum neutron economy for light water reactors (LWRs), resulting in lower fuel enrichment requirements. Deployment of the more recent generations of zirconium alloys and advances in fuel designs (such as debris protection), coupled with optimized guidelines for fuel operation, have resulted in further improvements in fuel reliability by many orders of magnitude, essentially approaching zero fuel failures [2].

While the performance of today's zirconium alloy cladding is optimal under normal operating conditions, beyond design basis accident scenario limitations exist that, in turn, reduce safety margins for the integral system. Note that the outcome of a severe accident scenario in an LWR is largely dominated by the type and availability of safety systems in place and the sequence of events. However, the materials in the core can affect the course of accident progression. In loss of coolant scenarios, decay heat coupled with poor heat conductance in steam drives up the core temperature. The onset of physical and chemical degradation phenomena takes place at temperatures above approximately $800^{\circ} \mathrm{C}$, where zirconium alloy fuel cladding balloons and bursts [3]. As the core temperature increases, detrimental interaction between core constituents and steam oxidation exacerbates core degradation processes. Specifically, deposition of a large amount of enthalpy (due to exothermic steam oxidation of zirconium) in addition to what is deposited directly by decay heat [4] increases the heat removal requirements to cool the core.

Given these limitations, an international effort is underway to examine alternate fuel concepts that provide higher safety margins under severe accidents. These are referred to as accident tolerant fuel (ATF) concepts [5]. In particular, alternate cladding materials are being investigated with significantly reduced oxidation kinetics in high-temperature steam environments when compared to zirconium alloys [6-9], which could reduce heating and hydrogen generation rates.

Analyses were performed to provide preliminary insight into the neutronic aspects of the use of alternate fuel cladding concepts in PWR cores. This is deemed necessary to guide broader fuel development and qualification efforts. Though many alternate clad materials are being examined as candidate ATF cladding concepts, this paper focuses on specific iron-based and silicon carbide options. These cladding materials are compared with the reference zirconium alloy clad fuel pins using results for depletion calculations, spectral analyses, reactivity coefficient calculations, radial fission power, and plutonium breeding analysis. Finally, variations in fuel costs among the cladding material options were estimated based upon relative amounts of urania $\left(\mathrm{UO}_{2}\right)$ in each design. At this time, the scope of the study has been limited to single fuel rods in a PWR; future work should expand this to assembly-level or full-core analyses.

\section{I.B. Cladding Concepts Evaluated}

\section{Austenitic Steels and Ferritic Alloys}


Two austenitic stainless steels, types 310 (310SS) and 304 (304SS), as well as two ferritic alloys, a basic FeCrAl and the $\mathrm{APMT}^{\mathrm{TM}}$ alloy, were investigated during this study. Type 304SS represents the generic $18 \mathrm{Cr}-8 \mathrm{Ni}$ type austenitic steels that were used as cladding during the early decades of nuclear energy to the 1980s [10]. Although 304SS does not offer exceptional oxidation resistance at high temperatures [8], it represents a suitable case to study because of its historical use. Type 310SS contains higher chromium and nickel contents and exhibits hightemperature steam oxidation resistance by forming a protective $\mathrm{Cr}_{2} \mathrm{O}_{3}$ scale under those conditions [7]. The ferritic alloys contain aluminum and, therefore, form an even more protective $\mathrm{Al}_{2} \mathrm{O}_{3}$ scale under high temperature steam oxidation conditions [7].

When compared to zirconium alloys, the high strength offered by iron-based alloys coupled with their reduced susceptibility to cladding thickness loss as a result of corrosion under normal operating conditions allows for a reduction in the designed cladding thickness and, thus, an increase in pellet size (assuming a constant pitch-to-diameter ratio [P/D]). A review of historic iron-based cladding [10] noted that reduced cladding thickness, increased fuel enrichment, and increased fuel stack heights all were methods used in the past to achieve similar fuel cycle lengths between zirconium alloy and iron alloy clad fuel assemblies in LWRs. The former two schemes will be considered in this study for the cladding alloys of interest. The results in this manuscript expand upon a set of preliminary results provided earlier [11].

\section{Silicon Carbide Cladding}

Silicon carbide ( $\mathrm{SiC}$ ) applications in nuclear systems date back to the 1960s for use in hightemperature gas reactors. The material has not yet been used as cladding for nuclear fuel; however, $\mathrm{SiC} / \mathrm{SiC}$ composites ( $\mathrm{SiC}$ fibers embedded in a $\mathrm{SiC}$ matrix) have gained commercial traction in high-temperature hostile environments such as industrial gas engines and components in aircraft engines. Because of favorable neutronics and pseudo-ductility, SiC/SiC composites have been investigated over the past decade as potential cladding and core constituent materials in LWRs [12-14]. Utilization of SiC-based materials as fuel cladding is associated with certain unfavorable characteristics, namely elevated fuel temperatures due to low thermal conductivity of irradiated $\mathrm{SiC}[15,16]$ and large stresses that could result in loss of hermeticity expected from these structures [17]. However, the exceptional oxidation resistance [9] and strength of SiCbased materials in high-temperature steam environments render them worthy candidates for consideration in this study of ATF concepts. The composition of the $\mathrm{SiC}$ cladding is described in the following section.

\section{METHODOLOGY AND INPUT PARAMETERS}

\section{II.A. Pin Cell and Lattice Modeling}

To model the neutronic behavior of the alternate cladding materials, simple two-dimensional (2D) pin cell analyses were performed using SCALE/TRITON from SCALE 6.1.2 [18-20]. The CENTRM module from SCALE was used to produce resonance-shielded 238-group cross sections based on ENDF/B-VII.0 [21] nuclear data. TRITON couples the 2-D radiation transport code NEWT with ORIGEN for isotopic decay and depletion calculations. This system is capable 
of performing activation calculations in the clad as well as depletion calculations in the fuel. Therefore, these calculations accounted for clad composition changes due to neutron absorption in the cladding.

Modeling the fuel as a single repeating pin cell with reflective boundary conditions allowed for a large number of cases to be run in a short time, with each case containing numerous perturbations and iterations. Figure 1 depicts the TRITON model of the reference case pin geometry based on a Westinghouse $17 \times 17$ PWR fuel rod. The polygonal geometry shown below is the TRITON representation of a cylindrical geometry.

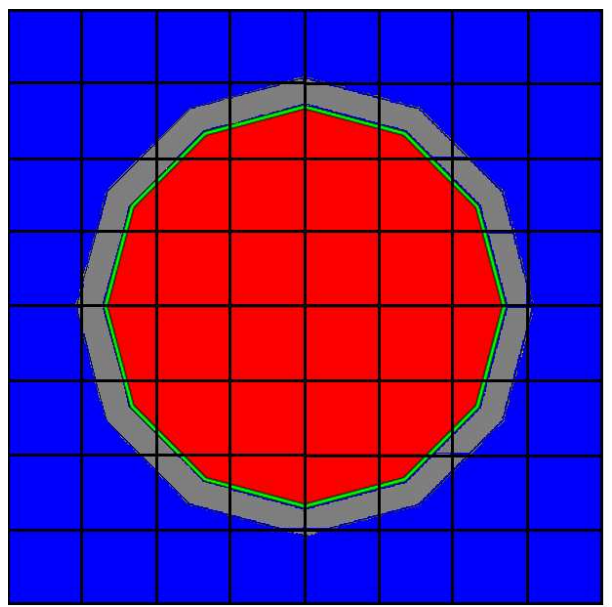

Fig. 1. Westinghouse $17 \times 17$ pressurized water reactor pin cell model.

The inner red region represents the $\mathrm{UO}_{2}$ pellet fuel used in all cases. The surrounding green and gray rings denote the gas gap and cladding material, respectively. Finally, the blue surrounding region represents the borated water coolant. Throughout this study, P/D and the pellet-cladding gap were kept constant at 1.326 and $82.55 \mu \mathrm{m}$, respectively. The cladding thickness and $\mathrm{UO}_{2}$ fuel pellet radius were adjusted in cases where cycle length requirements were not met; the fuel pellet radius was adjusted to maintain a constant gap thickness as the inner diameter of the clad changed to achieve a desired cladding thickness. An average value of $630 \mathrm{ppm}$ boron was placed in the water coolant to simulate the letdown of boron concentration from beginning of cycle to end of cycle (EOC). For the Zircaloy base case and metallic alloys (310SS and FeCrAl), the temperature of the fuel was kept at an average of $900 \mathrm{~K}$, while the cladding and gap were modeled at $600 \mathrm{~K}$ [22]. Due to a reduction in conductivity when using SiC cladding, the temperature of the fuel was raised to $1,100 \mathrm{~K}$, and the temperature of the cladding and gap were raised to $700 \mathrm{~K}$ [17]. The borated water in the system was modeled at $580 \mathrm{~K}$ at a constant density of $0.7119 \mathrm{~g} / \mathrm{cm}^{3}$ for all cases.

To verify the pin cell calculations, a 2 -D quarter lattice of $8.5 \times 8.5$ pins was modeled in TRITON with reflective boundary conditions to represent one-fourth of a $17 \times 17$ Westinghouse PWR assembly, as shown in Fig. 2. The larger rings placed within the lattice represent guide tube and instrumentation tube locations; there are 25 such locations in a standard Westinghouse $17 \times 17$ assembly. Initial results from these calculations indicate a small bias between pin-cell and lattice calculations; however, the overall trends observed in pin-cell parametric studies remain consistent at the assembly level. 


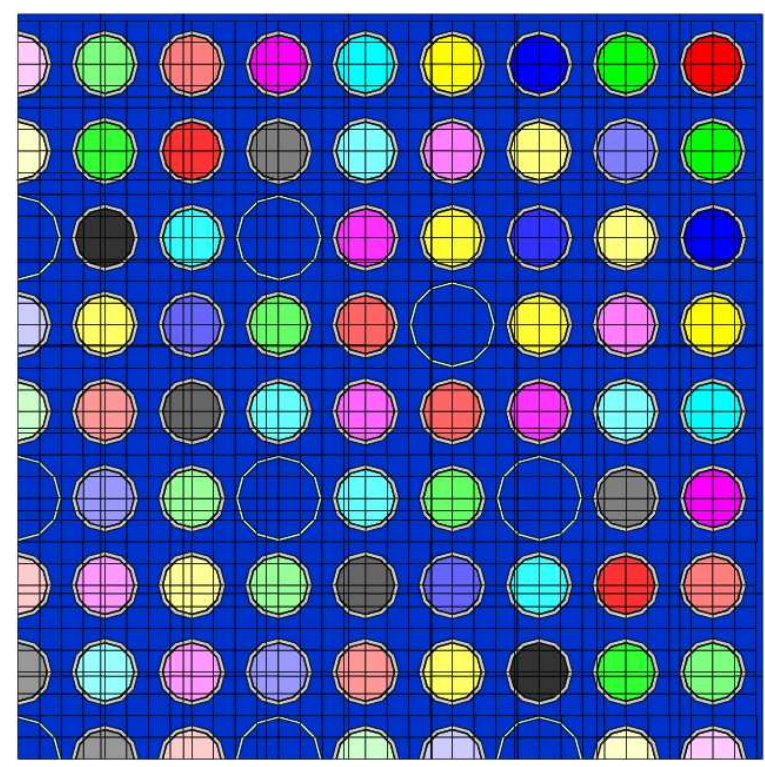

Fig. 2. Westinghouse $17 \times 17$ pressurized water reactor lattice model, with independent depletion mixtures indicated by different colors in the fuel pins.

\section{II.B. Input Parameters}

Table I provides the cladding materials examined in this study along with their detailed elemental compositions. This list includes a baseline zirconium alloy (Zircaloy-4), austenitic stainless steels (304SS and 310SS), generic and commercial variants of iron-chromiumaluminum alloys (FeCrAl and $\mathrm{APMT}^{\mathrm{TM}}[23]$, respectively), and $\mathrm{SiC}$.

Table I. Cladding Compositions Used for Fuel Reactivity Calculations

\begin{tabular}{|c|c|c|c|c|c|c|c|c|c|c|c|c|c|}
\hline Material & & $\mathbf{F e}$ & $\mathrm{Cr}$ & Al & $\mathbf{Z r}$ & $\mathbf{N i}$ & Sn & Mn & Mo & $\mathbf{Y}$ & $\mathbf{S i}$ & Hf & C \\
\hline Zircaloy & & 0.15 & 0.1 & & 98.26 & & 1.49 & & & & & & \\
\hline 304SS & & 71.35 & 18.9 & & 0 & 8.35 & & 0.7 & 0.27 & & 0.42 & & \\
\hline 310SS & $\frac{8}{3}$ & 52.55 & 25.22 & & 0 & 19.51 & & 1.9 & 0.122 & & 0.7 & & \\
\hline FeCrAl & & 75 & 20 & 5 & 0 & & & & 0 & & 0 & & \\
\hline APMT & & 69.79 & 21.6 & 4.9 & 0.1 & & & & 2.8 & 0.12 & 0.53 & 0.16 & \\
\hline $\mathrm{SiC}$ & & & & & & & & & & & 70.08 & & 29.92 \\
\hline Zircaloy & & 0.24 & 0.17 & & 98.43 & & 1.15 & & & & & & \\
\hline 304SS & & 70.44 & 20.04 & & & 7.84 & & 0.7 & 0.16 & & 0.82 & & \\
\hline 310SS & $\frac{D^{0}}{\pi}$ & 51.72 & 26.66 & & & 18.27 & & 1.9 & 0.07 & & 1.37 & & \\
\hline FeCrAl & & 70.2 & 20.11 & 9.69 & & & & & & & & & \\
\hline APMT & & 65.84 & 21.89 & 9.57 & 0.06 & & & & 1.54 & 0.07 & 0.99 & 0.05 & \\
\hline $\mathrm{SiC}$ & & & & & & & & & & & 50 & & 50 \\
\hline
\end{tabular}


Table II lists the microscopic thermal absorption cross sections that correspond to each alternate cladding material investigated. Materials with higher absorption properties are expected to have a greater effect on neutron economy as more neutrons are absorbed in the cladding before being captured in the $\mathrm{UO}_{2}$ fuel region. Although the absorption properties of a given material are dependent on neutron energy, average thermal cross sections are representative of neutron energies after they have been slowed down by the moderator, which is the energy range where most fission reactions occur in a PWR. 


\section{Table II. Density and Microscopic Thermal Neutron Absorption Cross Section for Various Cladding Materials [11]}

\begin{tabular}{ccc}
\hline Material & $\begin{array}{c}\text { Density } \\
\left(\mathbf{g} / \mathbf{c m}^{\mathbf{3}}\right)\end{array}$ & $\begin{array}{c}\text { Microscopic thermal } \\
\text { neutron absorption } \\
\text { cross section (barns) }\end{array}$ \\
\hline Zircaloy & 6.56 & 0.20 \\
$\mathbf{3 0 4 S S}$ & 7.9 & 2.86 \\
$\mathbf{3 1 0 S S}$ & 8.03 & 3.21 \\
FeCrAl & 7.1 & 2.43 \\
APMT & 7.3 & 2.47 \\
$\mathbf{S i C}$ & 2.58 & 0.086 \\
\hline
\end{tabular}

\section{II.C. Geometric and Enrichment Parameters}

For reactivity calculations, a number of fuel rod geometries were considered. A standard PWR $17 \times 17$ fuel bundle [24] with $4.9 \%$ enriched urania $\left(\mathrm{UO}_{2}\right)$ pellets was chosen as the reference case. The density of the $\mathrm{UO}_{2}$ pellet is $10.47 \mathrm{~g} / \mathrm{cm}^{3}$, which is about $96 \%$ of theoretical density. Table III provides the various geometries used during reactivity calculations. Case 1 is the reference case; the other cases increase heavy metal and fissile loading in the assembly by either increasing the pellet diameter at the expense of reducing cladding thickness (Cases 2-4) or increasing uranium enrichment (Cases 5-8). Analyses were performed for all cladding material options for Cases 1-8; Case 9 was analyzed only for $\mathrm{SiC}$ to represent the thicker cladding structures demonstrated to date for SiC-based materials [25].

Table III. Various Rod Geometries used for Reactivity Calculations

\begin{tabular}{cccccccc}
\hline Case \# & $\begin{array}{c}\Delta \mathbf{U O}_{2} \\
\text { Volume }\end{array}$ & $\begin{array}{c}\text { Pellet OD } \\
{[\mathbf{m m}]}\end{array}$ & $\begin{array}{c}\text { Gap } \\
\text { Thickness } \\
{[\boldsymbol{\mu m}]}\end{array}$ & $\begin{array}{c}\text { Clad ID } \\
{[\mathbf{m m}]}\end{array}$ & $\begin{array}{c}\text { Clad OD } \\
{[\mathbf{m m}]}\end{array}$ & $\begin{array}{c}\text { Clad } \\
\text { Thickness } \\
{[\boldsymbol{\mu m}]}\end{array}$ & $\begin{array}{c}\mathbf{U} \\
\text { enrichment }\end{array}$ \\
\hline 1 (ref) & 0 & 8.1915 & 82.55 & 8.3566 & 9.4996 & 571.5 & $4.9 \%$ \\
2 & $3.5 \%$ & 8.3345 & 82.55 & 8.4996 & 9.4996 & 500 & $4.9 \%$ \\
3 & $8.5 \%$ & 8.5345 & 82.55 & 8.6996 & 9.4996 & 400 & $4.9 \%$ \\
4 & $13.7 \%$ & 8.7345 & 82.55 & 8.8996 & 9.4996 & 300 & $4.9 \%$ \\
5 & 0 & 8.1915 & 82.55 & 8.3566 & 9.4996 & 571.5 & $5.5 \%$ \\
6 & 0 & 8.1915 & 82.55 & 8.3566 & 9.4996 & 571.5 & $6.0 \%$ \\
7 & 0 & 8.1915 & 82.55 & 8.3566 & 9.4996 & 571.5 & $6.5 \%$ \\
8 & 0 & 8.1915 & 82.55 & 8.3566 & 9.4996 & 571.5 & $7.0 \%$ \\
9 & $-14.9 \%$ & 7.5565 & 82.55 & 7.7216 & 9.4996 & 889 & $5.5 \%$ \\
\hline
\end{tabular}

Notes: $\mathrm{OD}=$ Outer Diameter; ID = Inner Diameter.

\section{II.E. End of Cycle Reactivity Calculations}


An analytical method was applied to the single-pin depletion results to approximate a multibatch loading scheme in a modern PWR. Figure 3 shows a typical core configuration found in a three-batch Westinghouse PWR. Table IV provides batch-specific parameters that were used and are typical for the type of loading scheme portrayed in Fig. 3; core volume fractions and relative assembly powers were used to determine the effective full power days (EFPDs) for each batch of fuel at the end of cycle.

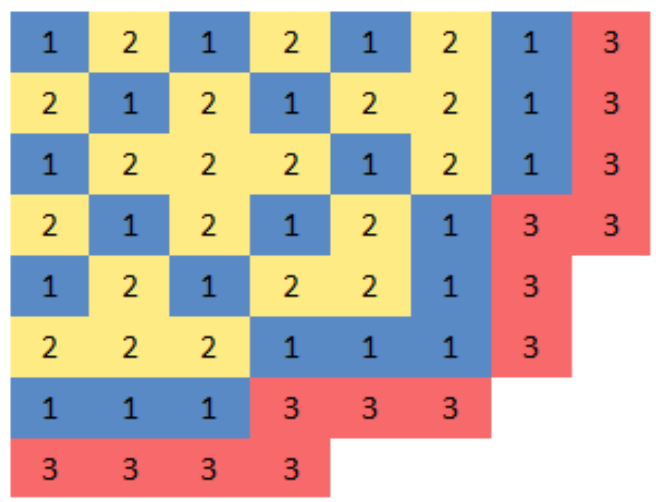

Fig. 3. Assumed pressurized water reactor core configuration of batch-specific loading pattern.

Table IV. Assumed Batch-dependent Assembly Counts, Core Volume Fractions, Relative Assembly Powers, and EFPDs for a Typical Westinghouse PWR

\begin{tabular}{ccccc}
\hline $\begin{array}{c}\text { Batch } \\
\left(\boldsymbol{e}_{\boldsymbol{b}}\right)\end{array}$ & $\begin{array}{c}\text { Number of } \\
\text { Assemblies }\end{array}$ & $\begin{array}{c}\text { Core } \\
\text { Fraction } \\
\text { Vol \% }\left(\boldsymbol{V}_{\boldsymbol{b}}\right)\end{array}$ & $\begin{array}{c}\text { Relative } \\
\text { Assembly } \\
\text { Power }\left(\boldsymbol{P}_{\boldsymbol{b}}\right)\end{array}$ & $\begin{array}{c}\text { EFPDs } \\
\text { Achieved at End of Cycle }\end{array}$ \\
\hline 1 & 73 & $38 \%$ & 1.25 & 627 \\
2 & 68 & $35 \%$ & 1.19 & 1221 \\
3 & 52 & $27 \%$ & 0.40 & 1420 \\
Total & $\mathbf{1 9 3}$ & $\mathbf{1 0 0 \%}$ & - & - \\
\hline
\end{tabular}

The core fractional volume was defined for each depletion cycle. For example, Cycle 1 consists of 73 assemblies and, thus, makes up 38\% of the 193 total assemblies present in a PWR core. The relative assembly power factor $\left(P_{b}\right)$ is the energy output per batch relative to the average energy of all cycles (from a typical Westinghouse PWR). The total EFPD represents the cycle EFPD obtained by weighting the EFPD increment for each batch by its core volume fraction. Batch 3 represents the discharged fuel with 1,420 EFPDs.

The magnitude of the infinite multiplication factor (k-infinity) at 627, 1,221, and 1,420 EFPDs was used to estimate the end of cycle (EOC) $\overline{\Delta k}_{\text {core }}$ for each fuel geometry that was simulated. In doing this, a method similar to the Linear Reactivity Model [26] was developed [27]. The EOC reactivity for each case was compared to that of a reference case (standard PWR fuel rod containing $\mathrm{UO}_{2}$ pellets). The core average eigenvalue difference can be estimated using Eq. (1): 


$$
\overline{\Delta k}_{\text {core }}=\frac{\sum_{b} x_{b}\left(e_{b}\right) P_{b} V_{b}}{\sum_{b} P_{b} V_{b}} .
$$

In this equation, $x_{b}$ is the difference in k-infinity between the fuel design under consideration and that of the reference case as a function of exposure $\left(e_{b}\right)$. The EOC EFPD values from Table IV were used to quantify the level of exposure each batch received. The power weighting factor $\left(P_{b}\right)$ approximates the power distribution in the core to provide a measure of contribution of each fuel batch to the overall core reactivity. Finally, the number of assemblies per fuel batch found in a given cycle of a PWR core is denoted by $V_{b}$.

\section{RESULTS}

\section{III.A. Depletion k-infinity Results}

Figure 4 shows k-infinity as a function of EFPDs in fuel rods with the standard PWR $17 \times 17$ geometry and various cladding materials. All models were depleted for 1,475 EFPDs to bound the expected value (1,420 EFPDs) after three 18-month cycles in PWR. The neutronic penalty/advantage associated with utilization of alternate cladding materials due to the differing neutron absorption in these materials is more easily seen in Fig. 5, where the difference in the k-infinity between the alternate cladding material and Zircaloy is shown for the reference case.

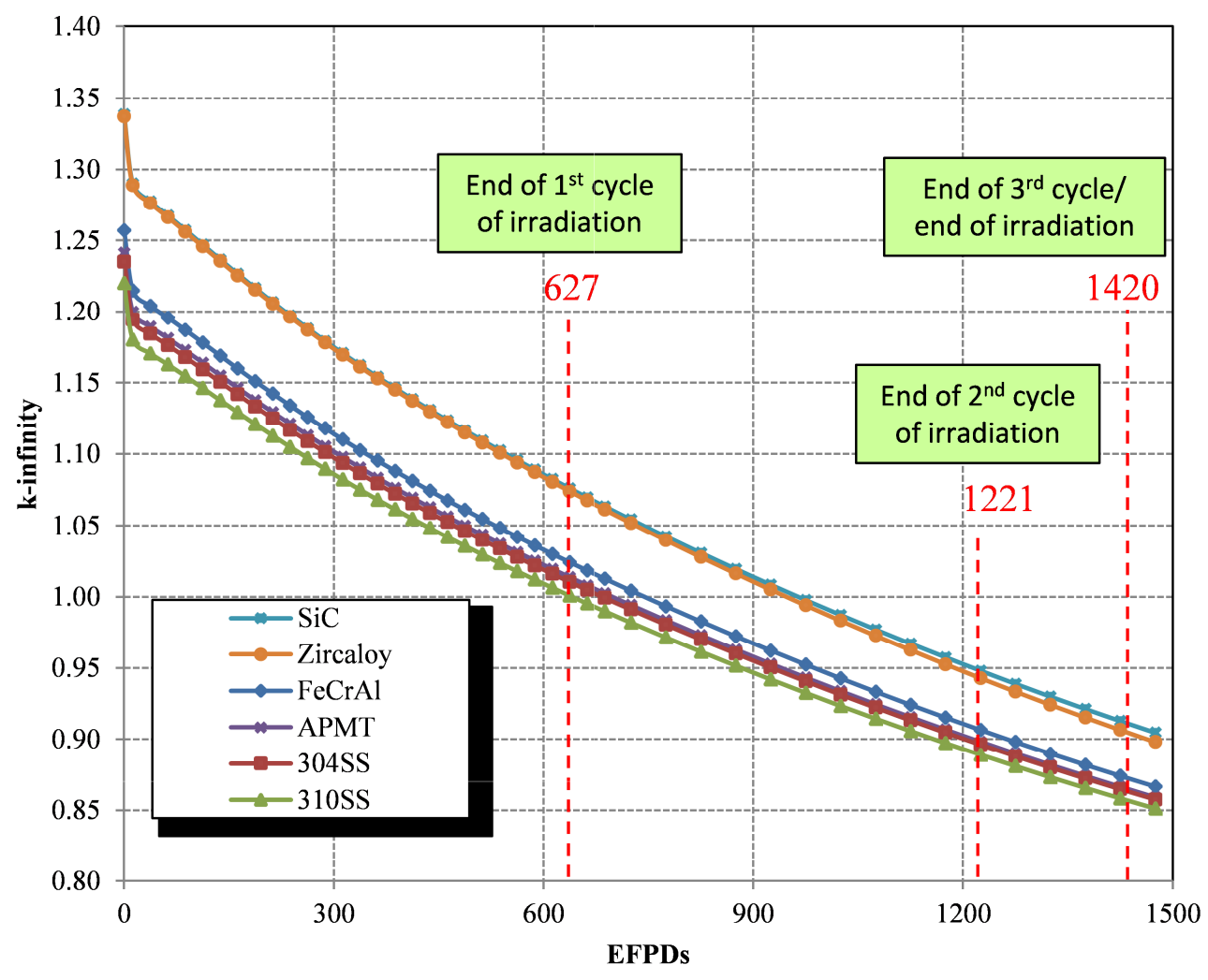


Fig. 4. Infinite multiplication factor vs. effective full power days for various cladding materials in standard pressurized water reactor $17 \times 17$ rod geometry.

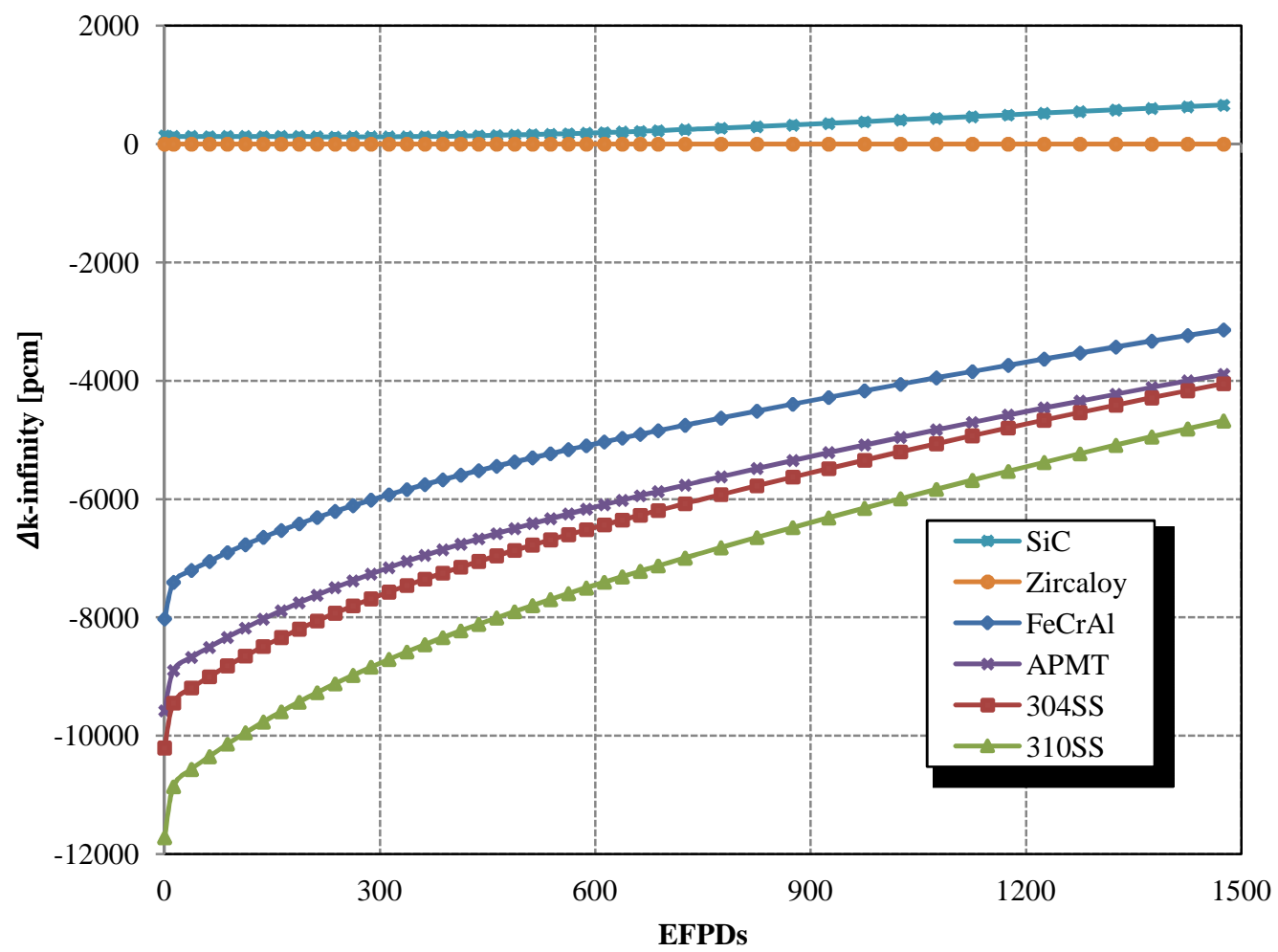

Fig. 5. $\Delta$ k-infinity from Zircaloy-4 clad fuel vs. effective full power days for various cladding materials.

The drop in reactivity found for 310SS, 304SS, APMT, and FeCrAl corresponds to a significant reduction in operational cycle length. As shown in Fig. 5, $\Delta \mathrm{k}$-infinity for those cladding materials decreases throughout the cycle. This phenomenon is due to increased plutonium breeding throughout the cycle in the presence of a harder neutron spectrum, as discussed in Section IV.A. The reactivity penalties at the end of three 18-month cycles for austenitic stainless steels (304SS and 310SS) were found to be $-4.2 \%$ and $-4.8 \% \Delta \mathrm{k}$-infinity respectively, while the ferritic alloys ( $\mathrm{FeCrAl}$ and APMT) were slightly less negative at $-3.2 \%$ and $-4.0 \%$. The less absorbing SiC cladding produced a positive $0.6 \% \Delta \mathrm{k}$-infinity at end of life (EOL).

To enhance the reactivity and increase the cycle length for those materials, modified fuel rod geometries or increased enrichment in the fuel are necessary. Accordingly, fuel rod designs conforming to Cases 2-8 in Table III are considered for alternate cladding concepts. For SiC, the cladding thickness was also increased in Case 9 to be representative of the thicker cladding structures demonstrated to date for SiC-based materials.

\section{III.B. End of Cycle Reactivity Calculations}

Table V displays the $\overline{\Delta k}_{\text {core }}$ corresponding to each cladding material for Cases $1-9$. The specific power in megawatts per metric tonne of uranium (MW/MTU) corresponds to the constant power 
of 18.0 MW/assembly modeled through the depletion cycle. Positive and equivalent $\overline{\Delta k}_{\text {core }}$ values with respect to the reference case (Case 1 with $4.9 \%$ enriched urania in Zircaloy-4 cladding) are highlighted in Table V. When the difference is zero, identical cycle lengths to the reference scenario are achieved.

\section{Table V. Cycle Reactivity Difference [ $\Delta \mathbf{k}_{\text {core }}$ ] for Alternate Fuel Cladding Concepts from the Reference PWR Fuel with Zircaloy-4 Cladding}

\begin{tabular}{ccccccccc}
\hline Case \# & $\begin{array}{c}\text { Clad Thickness } \\
(\boldsymbol{\mu} \mathbf{m})\end{array}$ & $\begin{array}{c}{ }^{235} \mathbf{U} \\
\text { Enrichment }\end{array}$ & $\begin{array}{c}\text { Specific Power } \\
(\text { MW/MTU) }\end{array}$ & 304SS & 310SS & FeCrAl & APMT & SiC \\
\hline $\mathbf{1}$ (ref) & 571.5 & $4.9 \%$ & 38.33 & -0.054 & -0.062 & -0.042 & -0.052 & 0.004 \\
$\mathbf{2}$ & 500 & $4.9 \%$ & 37.03 & -0.041 & -0.048 & -0.030 & -0.038 & - \\
$\mathbf{3}$ & 400 & $4.9 \%$ & 35.31 & -0.023 & -0.028 & -0.014 & -0.021 & - \\
$\mathbf{4}$ & 300 & $4.9 \%$ & 33.71 & -0.006 & -0.010 & 0.001 & -0.005 & - \\
$\mathbf{5}$ & 571.5 & $5.5 \%$ & 38.33 & -0.027 & -0.036 & -0.015 & -0.025 & - \\
$\mathbf{6}$ & 571.5 & $6.0 \%$ & 38.33 & -0.006 & -0.015 & 0.006 & -0.004 & - \\
$\mathbf{7}$ & 571.5 & $6.5 \%$ & 38.33 & 0.014 & 0.005 & 0.026 & 0.016 & - \\
$\mathbf{8}$ & 571.5 & $7.0 \%$ & 38.33 & 0.033 & 0.024 & 0.045 & 0.035 & - \\
$\mathbf{9}$ & 889 & $5.5 \%$ & 45.04 & - & - & - & - & 0.000 \\
\hline
\end{tabular}

Note: Positive and equivalent $\overline{\Delta k}_{\text {core }}$ values with respect to the reference case (Case 1 with $4.9 \%$ enriched urania in Zircaloy-4 cladding) are in highlighted cells.

Upon decreasing the cladding thickness and increasing the $\mathrm{UO}_{2}$ fuel pellet volume by nearly $14 \%, \mathrm{FeCrAl}$ was the only metallic alternate cladding material to meet lifetime requirements while maintaining a constant $4.9 \%$ fuel enrichment. SiC, which has slightly lower neutron absorption than Zircaloy (shown in Table II), exceeded 0.000 without any geometric alterations to the base case conditions. When setting up a conservative $\mathrm{SiC}$ model with a cladding thickness of 889 microns, increasing enrichment to $5.5 \%$ adds sufficient fissile material to meet lifetime requirements. Combinations of decreased cladding thickness and enrichment were investigated in the following section.

\section{III.C. Interpolation of Fuel Properties Matching EOC Values}

The necessary enrichment to match the fuel cycle length of the reference case was calculated in this section for various alternate cladding concepts. Given the higher strength of iron-based alloys when compared to zirconium-based alloys, a reduced cladding thickness of $350 \mu \mathrm{m}$ was considered for these cases. This is consistent with historic utilization of these materials as fuel cladding in LWRs [10]. The cladding thicknesses for the SiC and Zircaloy cases were kept at $571.5 \mu \mathrm{m}$, which represents a typical thickness for a Westinghouse PWR fuel rod. Although a broad range of alloys was initially considered, the subsequent calculations will focus on Zircaloy, FeCrAl, 310SS, and $\mathrm{SiC}$ as cladding materials.

Therefore, with these new geometric properties, enrichment was interpolated until an EOC value of 0.000 (+/- 0.001) was obtained from the respective k-infinity results. After multiple iterations, the enrichment and geometry combinations shown in Table VI were used for the remaining neutronics calculations. For all cases, an outer rod diameter of $0.94996 \mathrm{~cm}$ was kept constant, therefore maintaining a pitch-to-rod ratio of 1.326 so that the thermal hydraulics in the PWR 
system would not be affected drastically if commercialized.

Table VI. U-235 Enrichment Matching Cycle Length Requirements

\begin{tabular}{ccc}
\hline & $\begin{array}{c}\text { Cladding } \\
\text { Thickness } \\
(\boldsymbol{\mu m})\end{array}$ & $\begin{array}{c}\text { Required }{ }^{\mathbf{2 3 5} \mathbf{U} \%} \\
\text { Enrichment for Equivalent } \\
\text { EOC Value (0.000) }\end{array}$ \\
\hline $\begin{array}{c}\text { Zircaloy } \\
\text { (Standard Fuel) }\end{array}$ & 571.5 & 4.90 \\
FeCrAl & 350.0 & 5.06 \\
SiC & 571.5 & 4.81 \\
$\mathbf{3 1 0 S S}$ & 350.0 & 5.39 \\
\hline
\end{tabular}

Cladding materials 310SS and FeCrAl were modeled with an increased pellet diameter and reduced cladding thickness, while maintaining a constant pellet-clad gap thickness. This allows for increased heavy metal loading, thus reducing the ${ }^{235} \mathrm{U}$ enrichment required to match PWR cycle lengths when using Zircaloy. Because of reduced neutron absorption in the clad for SiC, a reduction in enrichment below $4.9 \%$ was possible while matching the reference EOC k-infinity.

In addition to interpolating enrichment with a fixed cladding thickness, the necessary cladding thickness for each material to achieve identical EOC k-infinity to that of the base case was also interpolated by fixing the enrichment of the $\mathrm{UO}_{2}$ fuel at $4.9 \%{ }^{235} \mathrm{U}$. Table VII provides the cladding thicknesses required for a 0.000 (+/- 0.001) EOC value. The amount of clad thinning presented in the following table is done purely on a neutronics basis to match lifetime requirements and does not account for the thermo-mechanical fuel performance constraints of the cladding concepts (e.g., maintaining cladding integrity during operations).

\section{Table VII. Cladding Thickness Matching Cycle Length Requirements}

\begin{tabular}{ccc}
\hline & $\begin{array}{c}\text { 235 U \% } \\
\text { Enrichment }\end{array}$ & $\begin{array}{c}\text { Cladding Thickness }(\boldsymbol{\mu m}) \\
\text { Required for Equivalent } \\
\text { EOC Value (0.000) }\end{array}$ \\
\hline $\begin{array}{c}\text { Zircaloy } \\
\text { (Standard Fuel) }\end{array}$ & 4.90 & 571.5 \\
FeCrAl & 4.90 & 302.2 \\
SiC & 4.90 & 606.7 \\
310SS & 4.90 & 226.3 \\
\hline
\end{tabular}

The geometric and enrichment specifications from Tables VI and VII were gathered into a single plot, Fig. 6, representing all simulations with parameter combinations expected to meet reactivity lifetime requirements in a PWR environment. The blue data point at the intersection of the abscissa and ordinate represents the Westinghouse $17 \times 17$ base case Zircaloy pin containing $4.9 \%$ enriched uranium and a cladding thickness of $571.5 \mu \mathrm{m}$. Fitting the data, a linear trend is shown when modifying fuel parameters. Any combination of enrichment and cladding thicknesses left and upward of the linear trend line shown for each material is expected to meet or exceed cycle length requirements. 


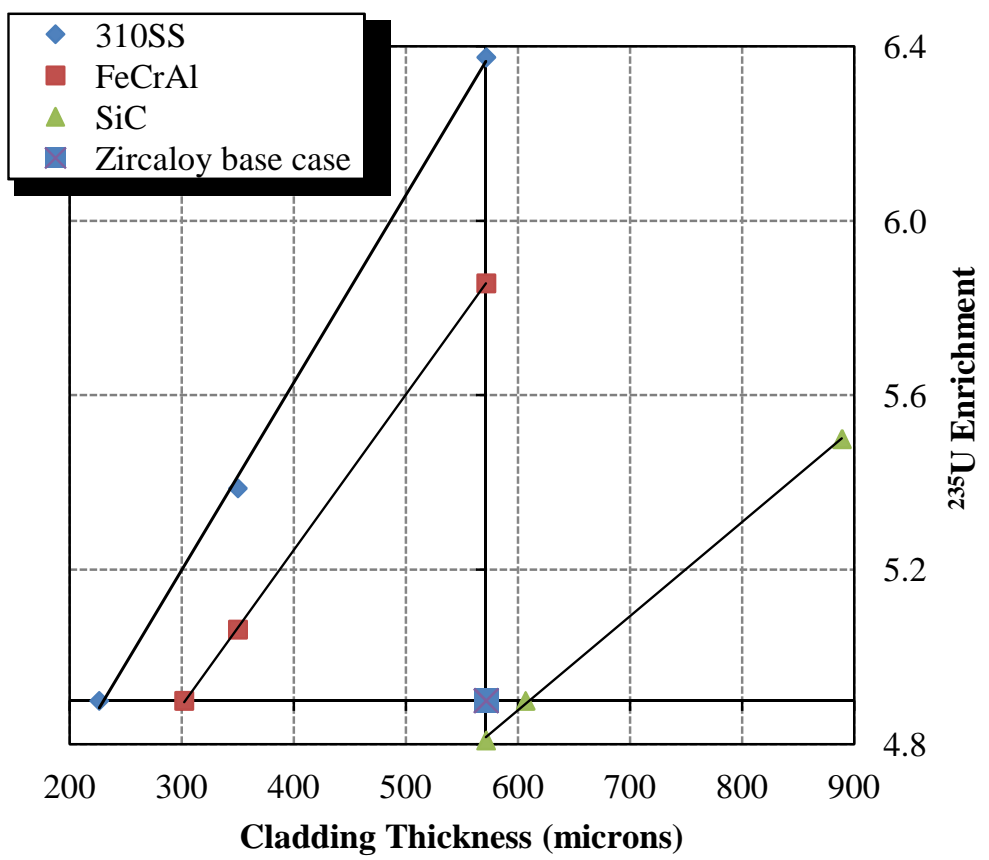

Fig. 6. Fuel parameters required to match the pressurized water reactor lifetime.

As mentioned previously, 310SS and FeCrAl contain elements with higher neutron absorption than Zircaloy; if enrichment is kept constant, a greater heavy metal loading is needed for these materials to match the cycle length of Zircaloy. This is achieved by using a thinner cladding while maintaining a constant P/D. Increased levels of ${ }^{235} \mathrm{U}$ enrichment also could help maintain the cycle length achieved by Zircaloy, but additional enrichment will increase fuel fabrication costs. From a safety and economic standpoint, data points closer to the bottom right of the plot signify fuel parameters that are more desirable because the enrichment and total heavy metal loading in the fuel are lowest, and clad integrity should be highest. An economic assessment quantifying the additional fuel costs of the above models is discussed in Section IV.D.

\section{III.D. Reactivity Coefficients}

In keeping with the safety standards of operational PWRs, it is imperative that each cladding material maintains negative moderator and void coefficients. Because only minor changes were made to the fuel enrichment, the Doppler coefficient was expected to be consistent with that of standard PWR fuel and was therefore not investigated in this study. Thus, moderator temperature and void reactivity responses were calculated for each alternate cladding case by perturbing the conditions of the coolant. To simulate the effective density changes of water for each temperature perturbation, a Fluid Properties Database Program from the National Institute of Standards and Technology was used [28]. When simulating the presence of superheated steam in the coolant, the density of water was decreased by the fraction of the void in the system. Table VIII summarizes the temperature and density perturbations made for each alternate cladding study. Perturbations branch from the nominal base case conditions, which are a moderator temperature of $580 \mathrm{~K}\left(0.7119 \mathrm{~g} / \mathrm{cm}^{3}\right)$ and $0 \%$ void. In all of the cases listed in Table VIII, the boron concentration was maintained at the average conditions of $630 \mathrm{ppm}$, and therefore the 
analysis is for representative fuel burnups rather than for accurate operating conditions; that effect is observed independently below.

\begin{tabular}{|c|c|c|c|}
\hline \multicolumn{2}{|c|}{ Moderator Temp Coefficient } & \multicolumn{2}{|c|}{ Moderator Void Coefficient } \\
\hline Temperature (K) & Density $\left(\mathrm{g} / \mathrm{cm}^{\mathbf{3}}\right)$ & Void (\%) & Density $\left(\mathrm{g} / \mathrm{cm}^{3}\right)$ \\
\hline 560 & 0.7521 & $0 \%$ & 0.7119 \\
\hline 570 & 0.7329 & $5 \%$ & 0.6763 \\
\hline 575 & 0.7227 & $10 \%$ & 0.6407 \\
\hline 580 & 0.7119 & $20 \%$ & 0.5695 \\
\hline 585 & 0.7005 & $40 \%$ & 0.4271 \\
\hline 590 & 0.6883 & $60 \%$ & 0.2848 \\
\hline 600 & 0.6612 & $80 \%$ & 0.1424 \\
\hline
\end{tabular}

Note: Nominal conditions are in bold.

To change the temperature and density parameters throughout the depletion cycle, branch perturbations were run in the SCALE model. Rather than deplete the fuel separately with each change in moderator property, a nominal model was run with the base conditions described above. From there, the isotopics of the nominal model were used at each timestep simulating instantaneous perturbations. Table IX represents the moderator temperature coefficient (MTC) at beginning of life (BOL), middle of life (MOL), and EOL. For these calculations as well as the remaining spectral and radial analyses done in later sections, thickness and enrichment specifications were taken from Table VI.

\section{Table IX. Moderator Temperature Coefficient Map Throughout Depletion $\left(\mathrm{pcm} \Delta \rho /{ }^{\circ} \mathrm{F}\right)$ with an $18^{\circ} \mathrm{F}$ Change in Coolant Temperature}

\begin{tabular}{cccc}
\hline & $\begin{array}{c}\text { Beginning } \\
\text { of Life } \\
\text { (BOL) }\end{array}$ & $\begin{array}{c}\text { Middle } \\
\text { of Life } \\
\text { (MOL) }\end{array}$ & $\begin{array}{c}\text { End } \\
\text { of Life } \\
\text { (EOL) }\end{array}$ \\
\hline Zircaloy & -14.8 & -25.8 & -34.5 \\
310SS & -16.9 & -25.9 & -34.4 \\
FeCrAl & -16.5 & -26.1 & -34.5 \\
SiC & -14.4 & -25.5 & -34.1 \\
\hline
\end{tabular}

These results show a negative MTC for each cladding material for a range of fuel burnups. As the fuel is depleted, less fissile material is present in the system, making reactivity more sensitive to changes in the moderator temperature and thus number density of water molecules. If a traditional boron letdown were to be simulated per cycle, the MTC at BOL would be less negative because of the additional boron in the moderator. Conversely, the MTC at EOL would be more negative because of the near zero boron concentration in the system. The analysis initially was done at a constant boron level $(630 \mathrm{ppm})$ to compare each cladding material relatively at a range of fuel burnups. Because the limiting case for MTC is when the boron concentration is highest during the cycle, the BOL coefficient was calculated for each case with 
1,300 ppm boron, which is representative of BOL boron conditions for a modern PWR. As expected, MTC for each alternate cladding material was slightly more positive with additional boron. Consistent to Table IX, SiC and Zircaloy produced the least negative MTC values at -9.4 and $-8.8 \mathrm{pcm} /{ }^{\circ} \mathrm{F}$, respectively, while $310 \mathrm{SS}$ and $\mathrm{FeCrAl}$ were slightly more negative at -12.2 and $-11.6 \mathrm{pcm} /{ }^{\circ} \mathrm{F}$, respectively.

In analyzing the void coefficient, the change in k-infinity upon the onset of superheated steam in the coolant was analyzed for each clad material. A steady decrease in k-infinity was found when the void fraction in the system coolant was increased. This and the MTC results in Fig. 6 represent negative coolant reactivity coefficients for each alternate cladding material case. The minimal variance among all four cases, including the Zircaloy base model, indicates that each cladding material will maintain operational standards similar to the other materials.

\section{DISCUSSION}

\section{IV.A. Spectral Hardening}

Spectral hardening was investigated next for the Fe-based, SiC and Zircaloy cladding materials under consideration. For this study, the neutron flux was calculated across a plane perpendicular to the axial direction of the rod at the center height spanning across the entire cell (fuel, cladding, and moderator). Lethargy was then calculated for each point so that the normalized flux per unit lethargy could be plotted at each of the 238 energy groups. Figure 7 corresponds to the flux spectra at BOL.

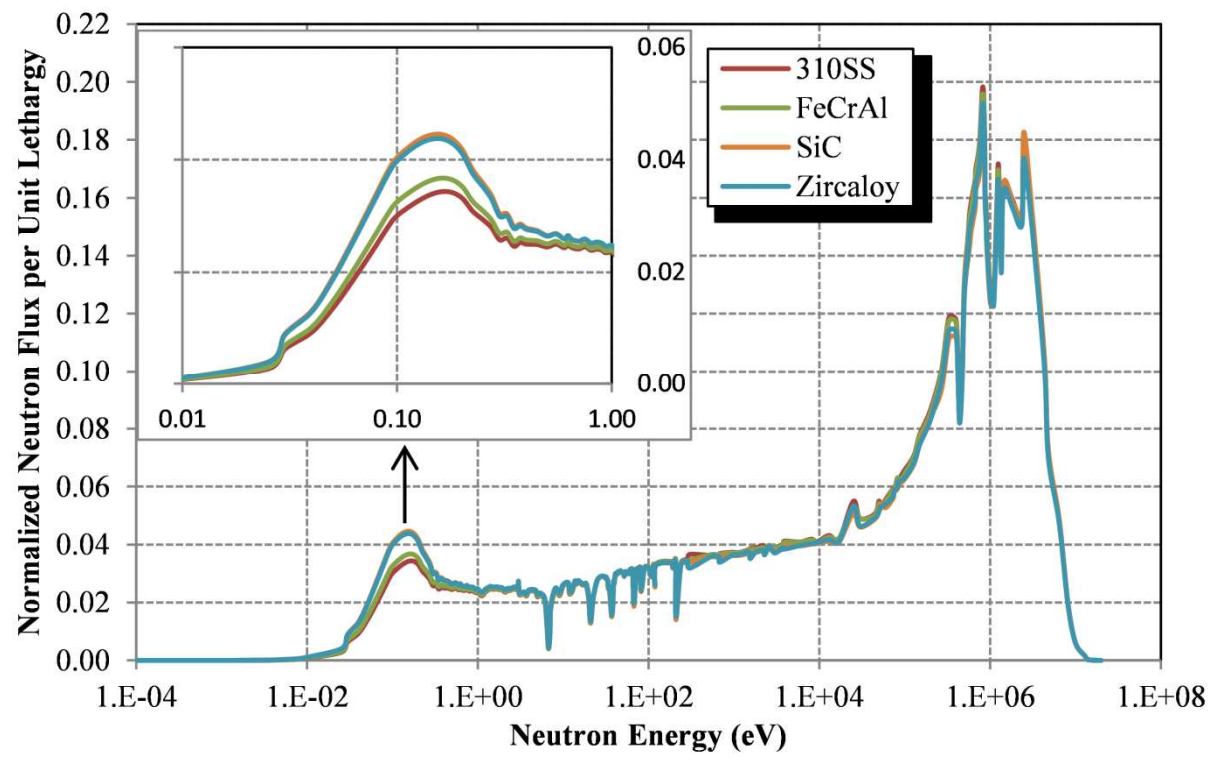

Fig. 7. Neutron flux spectrum at beginning of life.

The spectrum also was plotted at MOL and EOL. Analysis of the thermal peaks indicates that cladding materials containing higher absorbing isotopes produce a harder neutron spectrum throughout the depletion cycle. More thermal neutrons are being absorbed in the FeCrAl and 310SS cladding; therefore, the fraction of fast neutrons in the system increases. Thus, the thermal peak shown in the top left corner of Fig. 7 is lower for the higher absorbing materials and higher 
for Zircaloy and $\mathrm{SiC}$. For all four cases, a hardening of the spectrum was found from BOL to EOL as the thermal peaks at $0.1 \mathrm{eV}$ decrease and the fast peaks at $1 \mathrm{MeV}$ increase. This phenomenon is due to the depletion of overall fissile material and, in turn, an increased accumulation of fission products and actinides in the system.

\section{IV.B. Radial Profile Results}

The varying neutron absorption properties between the alternate cladding materials cause the fuel utilization factor to differ radially in the pellet. This in turn affects the rate of local burnup accumulation and plutonium production across the fuel pellet. Therefore, large differences in the radial power profile could affect the fuel microstructure evolution [29] and the onset of high burnup structure (HBS) formation [30]. By dividing the inner $\mathrm{UO}_{2}$ pellet into 10 equal areal rings, the radial power profile was analyzed. Figure 8 represents the pin cell calculation performed in SCALE when creating sub-rings in the fuel region. Both figures were taken from the Zircaloy reference model. The left represents the material plot of the pin cell, while the right represents the fast flux map. The higher flux of fast neutrons is denoted by red, while a lower flux is denoted by darker blue. The farthest outer ring represents the cladding, while the second most outer ring represents the gap.

(a)

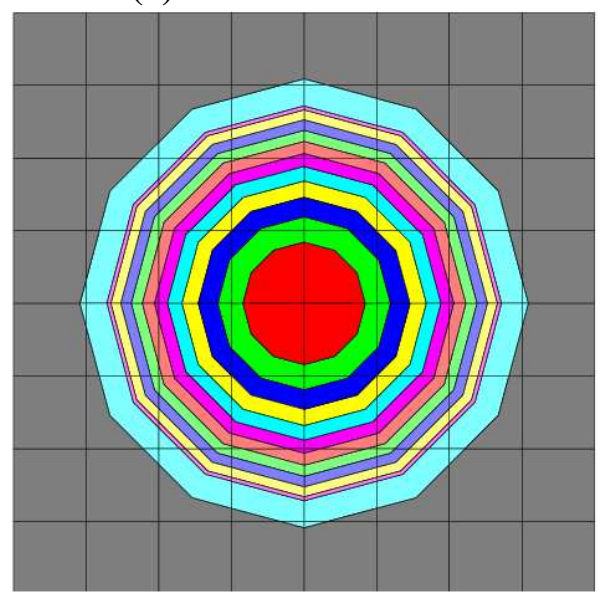

(b)

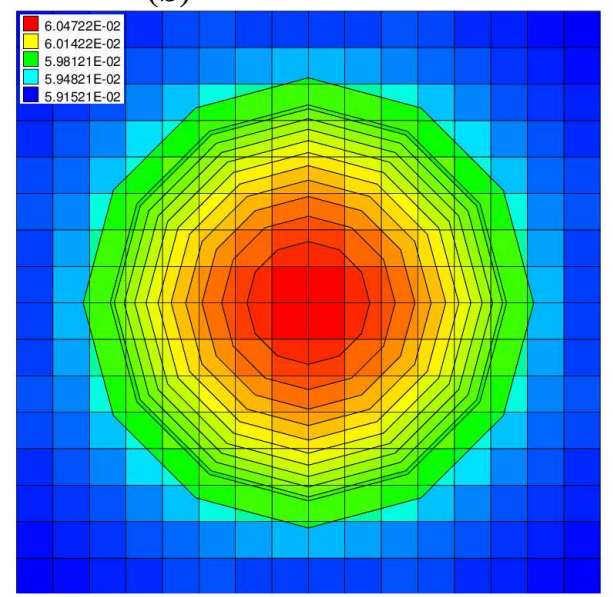

Fig. 8. Radial pin profile: material designation (a), fast neutron flux map (b).

Figure 9 plots the relative fission power in the inner and outer rings of the fuel pellet at BOL and EOL. The cladding thicknesses of $310 \mathrm{SS}$ and $\mathrm{FeCrAl}$ were modeled at $350 \mu \mathrm{m}$, while $\mathrm{SiC}$ and Zircaloy were modeled at $571.5 \mu \mathrm{m}$, thus leading to differences in fuel pellet radius among the different cases. Because of spatial self-shielding, where thermalized neutrons are shielded from the center of the fuel and are thus captured in the outer regions, the relative fission power is largest closer to the cladding and smallest in the center of the pellet. All four cladding materials exhibit similar fission power trends radially at BOL throughout the pin cell. This indicates that, despite differences in neutron absorption between the clad materials, the relative radial fission power distribution will not differ significantly.

As the depletion cycle continues, more plutonium is produced on the periphery of the fuel pellet than in the center of the fuel pellet because of spatial self-shielding of neutrons. This addition of 
fissile material causes a sharp increase in fission events in this region. As shown in the steeper curve, all four cases exhibit a relatively flat fission profile in regions 1 through 8 ; however, a sharp increase in fission power is evident in regions 9 and 10.

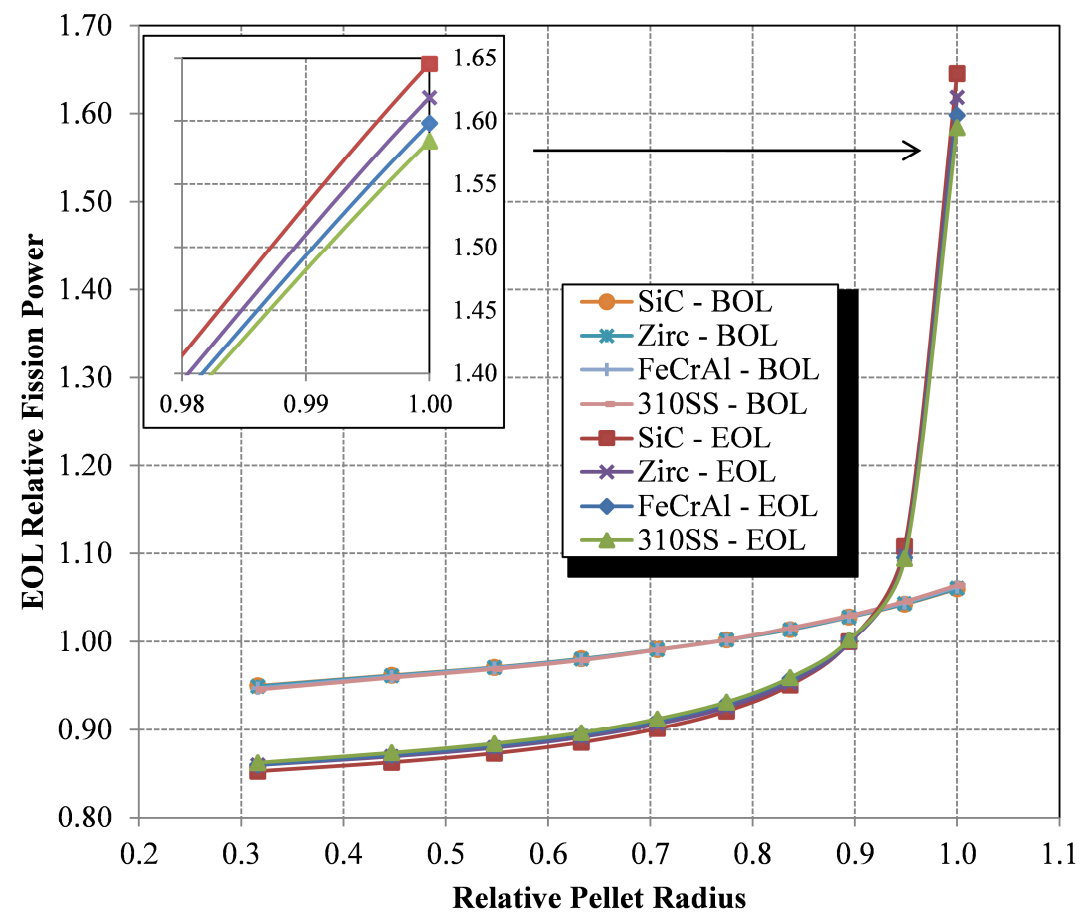

Fig. 9. Relative radial fission power distribution.

Taking a closer look at the outer region, the plot on the top left of Fig. 9 depicts the relative fission power in the 10th fuel ring. It can be seen that the lower absorbing materials ( $\mathrm{SiC}$ and Zircaloy) have a greater fission power relative to the rest of the pin when compared to FeCrAl and 310SS. This occurs because more thermal neutrons are escaping the cladding region after returning from the moderator and are being captured by the fissile plutonium in the outer ring. Although this difference in fission power between cladding materials is relatively small, the height of the four plot lines corresponds directly to the rank of thermal neutron absorption cross sections in ascending order.

To understand the above phenomenon better, the inventory of plutonium was plotted as a function of radial fuel rings. Figure 10 shows the concentration of ${ }^{239} \mathrm{Pu}$ as a function of fuel pellet region at MOL and EOL. Plutonium-239 was chosen because it is the largest contributor of fissions after ${ }^{235} \mathrm{U}$, thus greatly contributing to the reactor's reactivity lifetime. As shown in the plot, more ${ }^{239} \mathrm{Pu}$ is bred as the cycle continues. The data points in red represent the concentration of ${ }^{239} \mathrm{Pu}$ at MOL, while the points in blue represent the EOL. 


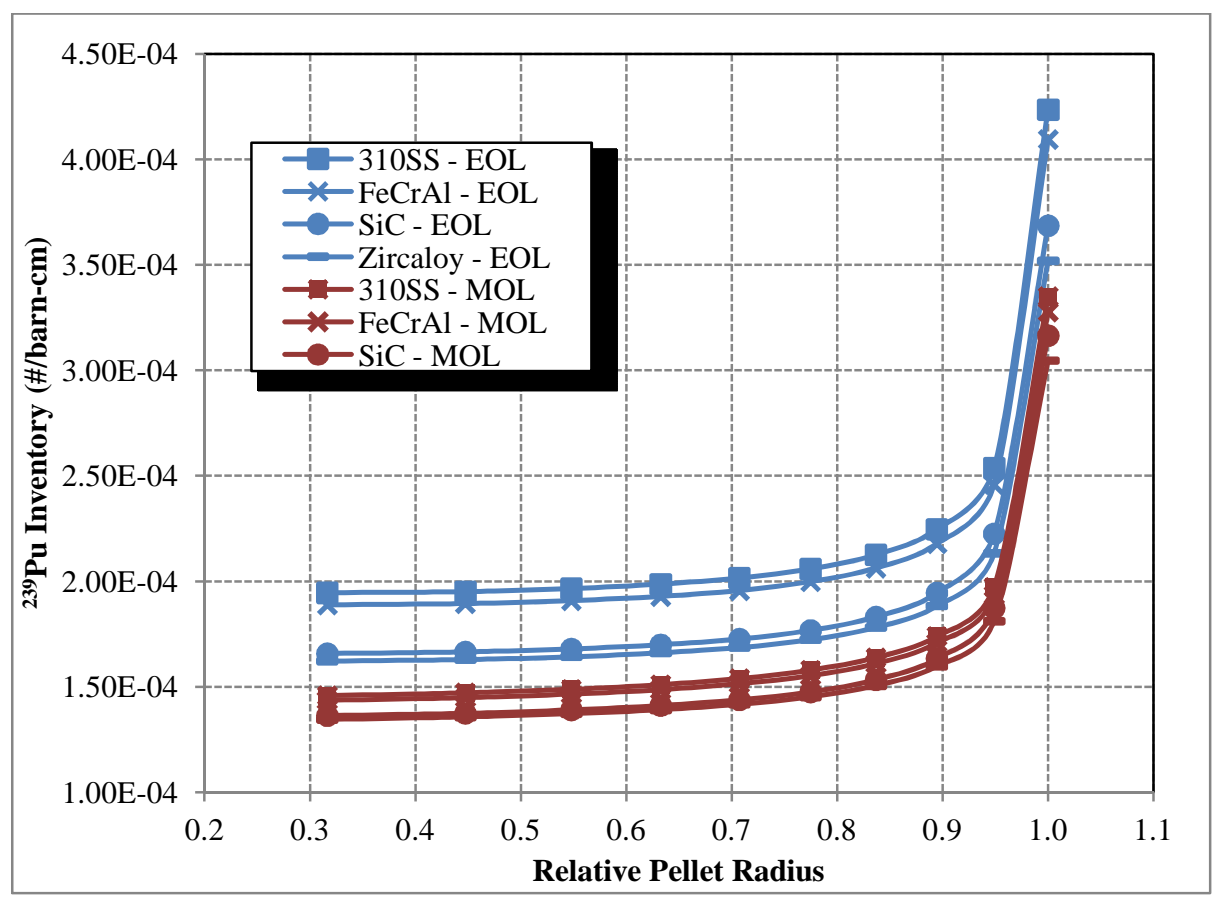

Fig. 10. Radial distribution of ${ }^{239} \mathrm{Pu}$ inventory at middle and end of life (MOL and EOL).

In Fig. 10, 310SS and FeCrAl clad fuels contain a higher concentration of plutonium than the lower absorbing SiC and Zircaloy claddings. This phenomenon is largely caused by the hardening of the neutron spectrum due to the higher thermal absorption in those claddings. This further emphasizes the trend that higher absorbing cladding materials yield a reduction in reactivity early in life but produce a slight upsurge in reactivity near EOL with a greater accumulation of plutonium. However, the differences observed in the radial power profile and the plutonium distribution require further analysis to determine if there is any resulting impact on the fuel performance.

\section{IV.D. Economic Assessment}

Fuel pellet costs for each design were calculated and compared to those of the base case Zircaloy design. Note that in the absence of known manufacturing and material costs for advanced cladding, the economic analysis does not take into consideration material and fabrication costs of the cladding, grid spacers, etc., but only considers the costs of the necessary enriched $\mathrm{UO}_{2}$ fuel pellets. The ore, conversion, and enrichment unit costs assumed were $\$ 35 / \mathrm{lb}, \$ 8.50 / \mathrm{lb}$ and $\$ 100 / \mathrm{kg}$ respectively [31]. The analysis results can be seen in Table X. Factoring enrichment costs of the appropriate heavy metal loading required, dollars per assembly is provided in the second-to-last column in Table X. Percent difference of fuel costs to that of the base case design is quantified in the final column. All cases below represent design combinations that meet PWR lifetime requirements for EOC reactivity. The lower bound thickness was set at 350 microns for 310SS and FeCrAl to maintain the integrity of the fuel rod, so the models containing cladding thicknesses below that value were excluded from the economic assessment.

Table X. Simple Assessment of Fuel Costs per Cladding Design 


\begin{tabular}{ccccccc}
\hline & $\begin{array}{c}\text { Clad Thickness } \\
(\boldsymbol{\mu m})\end{array}$ & $\begin{array}{c}\text { Enrich \% } \\
\mathbf{2 3 5}_{\mathbf{U}}\end{array}$ & $\begin{array}{c}\text { MTU } \\
\text { Loading/ } \\
\text { Assembly }\end{array}$ & $\begin{array}{c}\text { Uranium } \\
\text { Enrichment } \\
\text { Cost } \mathbf{( \$ / k g )})\end{array}$ & $\begin{array}{c}\text { Enriched } \\
\mathbf{U} \mathbf{O}_{\mathbf{2}} \text { Cost } \\
(\mathbf{\$} / \mathbf{a s s e m b l y )}\end{array}$ & $\begin{array}{c}\text { \% Diff cf. } \\
\text { Zirconium }\end{array}$ \\
\hline Zircaloy & 571.5 & 4.90 & 0.470 & 1,990 & 934,614 & - \\
FeCrAl-A & 571.5 & 5.86 & 0.470 & 2,449 & $1,150,185$ & $\mathbf{2 3 . 1}$ \\
FeCrAl-B & 350 & 5.06 & 0.522 & 2,068 & $1,079,144$ & $\mathbf{1 5 . 5}$ \\
SS310-A & 571.5 & 6.38 & 0.470 & 2,699 & $1,267,566$ & $\mathbf{3 5 . 6}$ \\
SS310-B & 350 & 5.39 & 0.522 & 2,223 & $1,160,028$ & $\mathbf{2 4 . 1}$ \\
SiC-A & 889 & 5.50 & 0.400 & 2,277 & 910,032 & $\mathbf{- 2 . 6 3}$ \\
SiC-B & 571.5 & 4.81 & 0.470 & 1,947 & 914,418 & $\mathbf{- 2 . 1 6}$ \\
SiC-C & 606.7 & 4.90 & 0.462 & 1,990 & 918,584 & $\mathbf{- 1 . 7 2}$ \\
\hline
\end{tabular}

Comparing each design with Zircaloy, designs containing 310SS or FeCrAl would require an increase of $15-36 \%$ in $\mathrm{UO}_{2}$ fuel pellet costs. If $\mathrm{SiC}$ were to replace Zircaloy as a cladding material (excluding any constraints in cladding minimum thickness and fuel pellet and pin performance), fuel costs would remain approximately the same or possibly be slightly lower.

\section{CONCLUSION}

The neutronic penalty associated with various alternate cladding materials was quantified in comparison to zirconium alloy in a PWR system. $\mathrm{UO}_{2}$ pin cell calculations were performed with Fe-based alloys, SiC and Zircaloy-4 cladding. The reactivity penalty in the reference PWR fuel geometry was most noticeable with austenitic stainless steels because they contain nickel as an alloying element. Two options were examined to increase fuel lifetime: the cladding thickness was reduced to allow for a larger pellet diameter, and enrichment of ${ }^{235} \mathrm{U}$ was increased.

An EOC reactivity method was established to quantify the overall reactivity difference between models during an 18-month PWR operating cycle. Various cases changing both enrichment and cladding thickness were analyzed, and the EOC values matching the standard PWR Zircaloy model were determined. To match lifetime requirements of standard $\mathrm{UO}_{2}$ fuel, cladding thickness would need to be reduced by roughly half when holding enrichment constant. Alternately, an increase in enrichment of $1-1.5 \%$ would be required when using FeCrAl or 310SS with the reference cladding thickness. It should be noted that FeCrAl and 310SS requiring enrichment above $5 \mathrm{wt} \%{ }^{235} \mathrm{U}$ would exceed the current license limit of fuel fabrication facilities. If commercialized, these fuel designs would necessitate additional fuel costs for relicensing of said facilities. Because of its relatively low neutron absorption, SiC could meet lifetime requirements even with a $0.1 \%$ reduction in enrichment.

Spectral analysis was performed for each alternate cladding material by plotting flux as a function of neutron energy, primarily to provide an insight into fuel performance considerations. FeCrAl and 310SS contain elements with higher neutron absorption cross sections than those in Zircaloy, which produced a harder neutron spectrum in the fuel pellet and led to increases in plutonium inventory of about $6.4 \%$ and $8.6 \%$, respectively. Dividing the fuel region into 10 radial rings, radial fission power and isotopic inventory were analyzed for each cladding material. For all cases, similar results were recorded regarding the concentration of plutonium throughout the pellet as well as the number of relative fissions occurring radially. However, a thermo-mechanical fuel performance analysis is required to determine the absolute effects. 
Reactivity coefficients were calculated for each alternate cladding model. By perturbing the moderator temperature and density, MTC was found to be negative at BOL and over a range of fuel burnups, and it was of similar magnitude for all cladding types. A simple economic assessment showed that fuel pellet costs for $\mathrm{FeCrAl}$ would increase by approximately $15 \%$ when slightly increasing enrichment and decreasing clad thickness to nearly half to meet PWR lifetime requirements.

\section{ACKNOWLEDGMENTS}

The aid and technical insight of Jess Gehin and Andrew Godfrey at Oak Ridge National Laboratory are gratefully acknowledged. The work presented in this paper was supported by the Advanced Fuels Campaign of the Fuel Cycle R\&D program in the Office of Nuclear Energy, US Department of Energy. This manuscript has been authored by UT-Battelle, LLC, under contract DE-AC05-00OR22725 with the U.S. Department of Energy. The United States Government retains and the publisher, by accepting the article for publication, acknowledges that the United States Government retains a non-exclusive, paid-up, irrevocable, world-wide license to publish or reproduce the published form of this manuscript, or allow others to do so, for United States Government purposes. 


\section{REFERENCES}

1. Adamson, R. B., Effects of neutron irradiation on microstructure and properties of Zircaloy, in Zirconium in the Nuclear Industry: 12th International Symposium, ASTM STP 1354, G. P. Sabol and G. D. Moan, Editors. 2000, American Society for Testing and Materials: West Conshohocken, Pa., p. 15-31.

2. Edsinger, K., EPRI and the zero fuel failures program. Nuclear News, 2010. 53(12): p. 40-43.

3. Hofmann, P., Current knowledge on core degradation phenomena, a review. Journal of nuclear materials, 1999. 270(1): p. 194-211.

4. Steinbrück, M., et al., Synopsis and outcome of the QUENCH experimental program. Nuclear Engineering and Design, 2010. 240(7): p. 1714-1727.

5. Zinkle, S. J., et al., Accident tolerant fuels for LWRs: A perspective. Journal of Nuclear Materials, 2014. 448: p. 374-379.

6. Cathcart, J. V., et al., Zirconium metal-water oxidation kinetics, IV: reaction rate studies, ORNL/NUREG-17. 1977, Oak Ridge National Laboratory.

7. Pint, B. A., et al., High Temperature Oxidation of Fuel Cladding Candidate Materials in Steam-Hydrogen Environments. Journal of Nuclear Materials, 2013. 440: p. 420-427.

8. Terrani, K. A., S. J. Zinkle, and L. L. Snead, Advanced oxidation-resistant iron-based alloys for LWR fuel cladding. Journal of Nuclear Materials, 2014. 448: p. 420-435.

9. Terrani, K. A., et al., Silicon Carbide Oxidation in Steam. Journal of American Ceramic Society, 2014.

10. Strasser, A., et al., An Evaluation of Stainless Steel Cladding for Use in Current Design LWRs, NP-2642. 1982, Electric Power Research Institute: Palo Alto, Calif.

11. George, N. M., K. A. Terrani, and J. J. Powers, Neutronic analysis of candidate accidenttolerant iron alloy cladding concepts, ORNL/TM-2013/121. 2013, Oak Ridge National Laboratory.

12. Yueh, K., D. Carpenter, and H. Feinroth, Clad in clay. Nuclear Engineering International, 2010. 55(666): p. 14-16.

13. Carpenter, D. M., An assessment of silicon carbide as a cladding material for light water reactors. 2010, Massachusetts Institute of Technology.

14. Yueh, K. and K. A. Terrani, Silicon carbide composite for light water reactor fuel assembly applications. Journal of Nuclear Materials, 2014. 448: p. 380-388.

15. Katoh, Y., et al., Continuous SiC fiber, CVI SiC matrix composites for nuclear applications: Properties and irradiation effects. Journal of Nuclear Materials, 2013.

16. Snead, L. L., et al., Handbook of SiC properties for fuel performance modeling. Journal of Nuclear Materials, 2007. 371(1-3): p. 329-377.

17. Ben-Belgacem, M., et al., Thermo-mechanical analysis of LWR SiC/SiC composite cladding. Journal of Nuclear Materials, 2014. 447(1-3): p. 125-142.

18. DeHart, M. D. and S. M. Bowman, Reactor physics methods and analysis capabilities in SCALE. Nuclear Technology, 2011. 174(2): p. 196-213.

19. Bowman, S. M., SCALE 6: Comprehensive Nuclear Safety Analysis Code System. Nuclear Technology, 2011. 174(2): p. 126-148.

20. SCALE: A Comprehensive Modeling and Simulation Suite for Nuclear Safety Analysis and Design, ORNL/TM-2005/39, Version 6.1, Available from Radiation Safety Information Computational Center at Oak Ridge National Laboratory as CCC-785. June 
2011, Oak Ridge National Laboratory: Oak Ridge, Tenn.

21. Chadwick, M., et al., ENDF/B-VII. 0: Next generation evaluated nuclear data library for nuclear science and technology. Nuclear data sheets, 2006. 107(12): p. 2931-3060.

22. Godfrey, A., VERA Core Physics Benchmark Progression Problem Specifications. 2012, Revision.

23. Kanthal APM and APMT Tube Material datasheet, AB Sandvik group, Sandviken, Sweden.

24. Fuel design data. Nuclear Engineering International, 2004. 49(September): p. 26-35.

25. Bloore, D. A., Reactor physics assessment of thick silicon carbide clad PWR fuels. 2013, Massachusetts Institute of Technology.

26. Driscoll, M. J., T. J. Downar, and E. E. Pilat, The linear reactivity model for nuclear fuel management. 1990: American Nuclear Society La Grange Park, Ill.

27. George, N. M., et al., Neutronics Studies Of Uranium-Bearing Fully Ceramic Microencapsulated Fuel For Pressurized Water Reactors. Nuclear Technology, 2014. In press.

28. Lemmon, E., et al., NIST12 Thermodynamic and Transport Properties of Pure FluidsNIST Standard Reference Database 23. 2007, Version 5.2.

29. Piro, M. H. A., et al., Coupled thermochemical, isotopic evolution and heat transfer simulations in highly irradiated UO2 nuclear fuel. Journal of Nuclear Materials, 2013. 441(1-3): p. 240-251.

30. Baron, D., et al., Discussion about HBS transformation in high burn-up fuels. Nuclear Engineering and Technology, 2009. 41(2): p. 199-214.

31. The Ux Consulting Company. http://www.uxc.com. Roswell, Ga. 2014. 